\title{
Photonics education in Switzerland on Bachelor and Master level triggered by industrial needs
}

\section{Markus Michler}

Markus Michler, "Photonics education in Switzerland on Bachelor and Master level triggered by industrial needs," Proc. SPIE 11143, Fifteenth Conference on Education and Training in Optics and Photonics: ETOP 2019, 111431K (2 July 2019); doi: 10.1117/12.2522485 


\title{
Photonics education in Switzerland on Bachelor and Master level triggered by industrial needs
}

\author{
Markus Michler*a \\ ${ }^{a}$ University of Applied Sciences and Technology Buchs, NTB, Institute for Micro- and \\ Nanotechnology, Buchs, Switzerland
}

\begin{abstract}
Over the past five years, Switzerland has undergone major changes in the field of photonics. Thanks to a well-positioned photonics industry and dedicated professional associations, new milestones were set in the area of training and further education, but also in research and development.

The main reason for the shortage of skilled workers in Switzerland was identified as the lack of education for qualified photonics engineers at bachelor and master level. Some years ago, the majority of the Swiss photonics companies syndicated under the patronage of Swissmem as its Photonics Division. In 2015 the members defined their requirements for young skilled workers and prepared a position paper "Bachelor in Photonics" in which Universities of Applied Sciences (UAS) were specifically asked to offer application-oriented bachelor programs.

The NTB with its long tradition in photonics R\&D decided to go for such a program. A team developed a curriculum for a photonics profile and implemented it as part of the "Bachelor in Systems Engineering". In autumn 2018 the first bachelor students graduated in photonics and were ready for an industrial career. The next step on the education roadmap in Switzerland was a specific profile in photonics as part of a nationwide Master Program in Engineering (MSE) for bachelor graduates of UAS. Here again the momentum came from the Swiss photonics industry. The planning and implementation of this unique master program is currently underway and is scheduled to start in September 2020.
\end{abstract}

Keywords: Bachelor in Photonics, Master in Photonics, Swiss photonics education, Swiss photonics industry, industry triggered education, SWISSMEM photonics section, NTN Swissphotonics, MSE Master of Science in Engineering,

\section{INTRODUCTION - PHOTONICS IN SWITZERLAND IN 2015}

In order to illustrate the situation of photonics in Switzerland five years ago, it is best to look at the economic figures, to observe the activities and the commitment of the corresponding lobbies and to take a closer look at education and training in the field of photonics.

\subsection{Swiss Photonics Industry}

The production volume for photonic products in Switzerland in 2015 reached approximately 3 billion Swiss francs (CHF) (approx. 2.6 billion Euro). Despite the depreciation of the Swiss franc, the Swiss share of European production remained almost constant over the last ten years. Production in Switzerland accounts for $3.6 \%$ of the European production (2015). Around 90\% of photonics production in Switzerland is exported [1]. Figure 1 (left) shows the trend in photonics production over the last 10 years between 2005 and 2015.

Laser material processing shows the largest sales volume. In 2015, lasers and laser equipment worth 830 million CHF were manufactured in Switzerland, followed by optical metrology \& image processing with a production volume of 710 million CHF. In third place, medical technology \& life science show up with a sales volume of 550 million CHF. Optical components \& systems with a volume of 390 million CHF are ranked fourth. Photovoltaics contributed a production volume of 270 million CHF in 2015. All other areas comprise a total volume of 175 million. This includes in particular optical-based communication and information technology. Figure 1 (right) shows a pie chart with the percentage distribution of the sales volumes. In Table 1 the different market segments, production volumes, market shares in Switzerland and worldwide as well as some global players in that field are listed.

*markus.michler@ntb.ch; phone +41 8175534 64; www.ntb.ch

Fifteenth Conference on Education and Training in Optics and Photonics: ETOP 2019, edited by

Anne-Sophie Poulin-Girard, Joseph A. Shaw, Proc. of SPIE Vol. 11143, 111431K · (c) 2019

SPIE, ICO, IEEE, OSA·CCC code: 0277-786X/19/\$18 · doi: 10.1117/12.2522485 
Photonics-Production Switzerland in Euro*

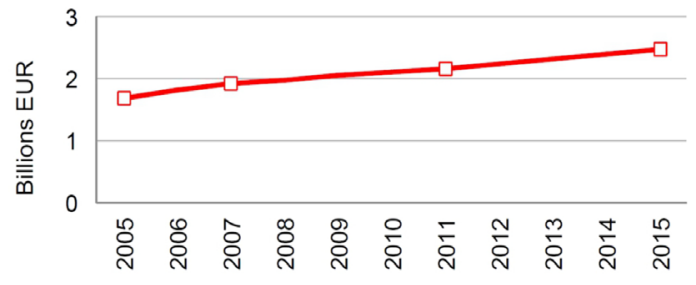

* Product range adapted to

European data
Photonics industry 2015 - Production volume Switzerland

Total: 3 billions CHF / ca. 9000 employees

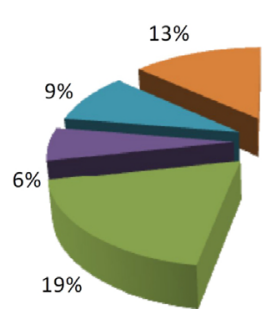

- laser material processing
Optical metrology and image
processing
Medical technology and Life
Science
- Optical Information Technology
- Photovoltaics
- Optical components and systems

OPTECH CONSULTING

Figure 1. (left) Trend in photonics production between 2005 and 2015; (right) pie chart with the percentage distribution of the sales volumes of the different market segments

Table 1. Market segments, production volumes, market shares in Switzerland and worldwide as well as some global players in the photonics sector in Switzerland in 2015

\begin{tabular}{|c|c|c|c|c|}
\hline Application Area & $\begin{array}{c}\text { Production } \\
\text { Volume }\end{array}$ & $\begin{array}{c}\text { Market Share } \\
\text { Switzerland }\end{array}$ & $\begin{array}{c}\text { Market Share } \\
\text { worldwide }\end{array}$ & Global Players \\
\hline $\begin{array}{l}\text { Laser material } \\
\text { processing }\end{array}$ & 830 million $\mathrm{CHF}$ & $29 \%$ & $7 \%$ & $\begin{array}{ll}- & \text { Trumpf } \\
- & \text { Lasag } \\
- & \text { Synova } \\
- & \text { NKT- Onefive }\end{array}$ \\
\hline $\begin{array}{l}\text { Metrology and image } \\
\text { processing }\end{array}$ & 710 million $\mathrm{CHF}$ & $24 \%$ & $2 \%$ & $\begin{array}{ll} & \text { Leica Geosystems (Hexagon) } \\
- & \text { Baumer }\end{array}$ \\
\hline $\begin{array}{l}\text { Medical technology } \\
\text { and life science }\end{array}$ & 550 million $\mathrm{CHF}$ & $19 \%$ & $1.5 \%$ & $\begin{array}{ll}\text { - } & \text { Leica Microsystems } \\
\text { - } & \text { Roche Diagnostics }\end{array}$ \\
\hline $\begin{array}{l}\text { Optical information } \\
\text { technology }\end{array}$ & 175 million $\mathrm{CHF}$ & $6 \%$ & - & $\begin{array}{ll}- & \text { Diamond SA } \\
- & \text { II-VI Laser Enterprise } \\
- & \text { Huber+Suhner } \\
\end{array}$ \\
\hline Photovoltaics & 270 million $\mathrm{CHF}$ & $9 \%$ & - & $\begin{array}{ll}- & \text { Meyer Burger } \\
- & \mathrm{ABB}\end{array}$ \\
\hline $\begin{array}{l}\text { Optical components } \\
\text { and systems }\end{array}$ & 390 million $\mathrm{CHF}$ & $13 \%$ & $2 \%$ & $\begin{array}{ll}- & \text { FISBA } \\
- & \text { SwissOptic } \\
- & \text { Safran-Vectronix }\end{array}$ \\
\hline
\end{tabular}

\subsection{Photonics advocacy groups and lobbies}

Swiss photonics industry is well organized in professional associations. In addition, Switzerland operates national thematic networks as interest groups for industry, research institutions and universities.

SWISSMEM is the leading association for SMEs and large companies in the Swiss machine, electrical and metal industry (MEM). Swissmem operates strong networks and promotes the national and international competitiveness of its members with a wide range of services. In 27 specialist groups and commissions, the member companies exchange views on technical issues or work on joint projects. The Swissmem Photonics Section is an industrial network for developers, manufacturers and suppliers of photonics and optical systems and their components as well as for representatives of universities and research institutions.

SWISSPHOTONICS is the National Thematic Network (NTN) for Photonics. It is the declared goal of Swissphotonics to improve the competitiveness of its members through the support of innovation forces. Swissphotonics initiates and supports competence workgroups, so called "Swiss National Photonic Labs". These labs bring together institutions that are interested in the same topics. Each lab is actively participating in its respective workgroup in the European public private partnership platform "Photonics21" where roadmaps and Horizon2020 calls are prepared. 
At present, Swissphotonics supports eight such labs that cover different important topics:

- SNAP: Swiss National Application Laboratory for Photonic Tools and Manufacturing

- SNFL: Swiss National Fiber Laboratory

- SSSL: Swiss National Laboratory for Solid State Lighting

- SPPL: Swiss Photonic Packaging Laboratory

- SNOP: Swiss National Optics Platform

- SEPP: Swiss Education Platform in Photonics

- SRPV: Swiss Research Platform in Photo Voltaics

- SNOS: Swiss National Laboratory for Optical Sensors.

\subsection{Photonics in Swiss education}

The Swiss education system is based on a three-level structure. After compulsory education, students decide at the age of 15 whether they want to pursue a primarily school-based career and move on to a grammar school, or whether they go for a basic professional education via an apprenticeship.

In contrast to other European neighboring countries like Austria, Germany, France or Italy, Switzerland traditionally has a large proportion of apprentices and a below average small number of grammar school pupils. The completion of a vocational baccalaureate following an apprenticeship qualifies students to study at a University of Applied Sciences (UAS), while the grammar school baccalaureate qualifies students to study at a university. Additionally, there is a large number of so-called "technical schools" in Switzerland for further technical training courses, most of which do not require a school leaving certificate. Figure 2 shows schematically the Swiss educational system.

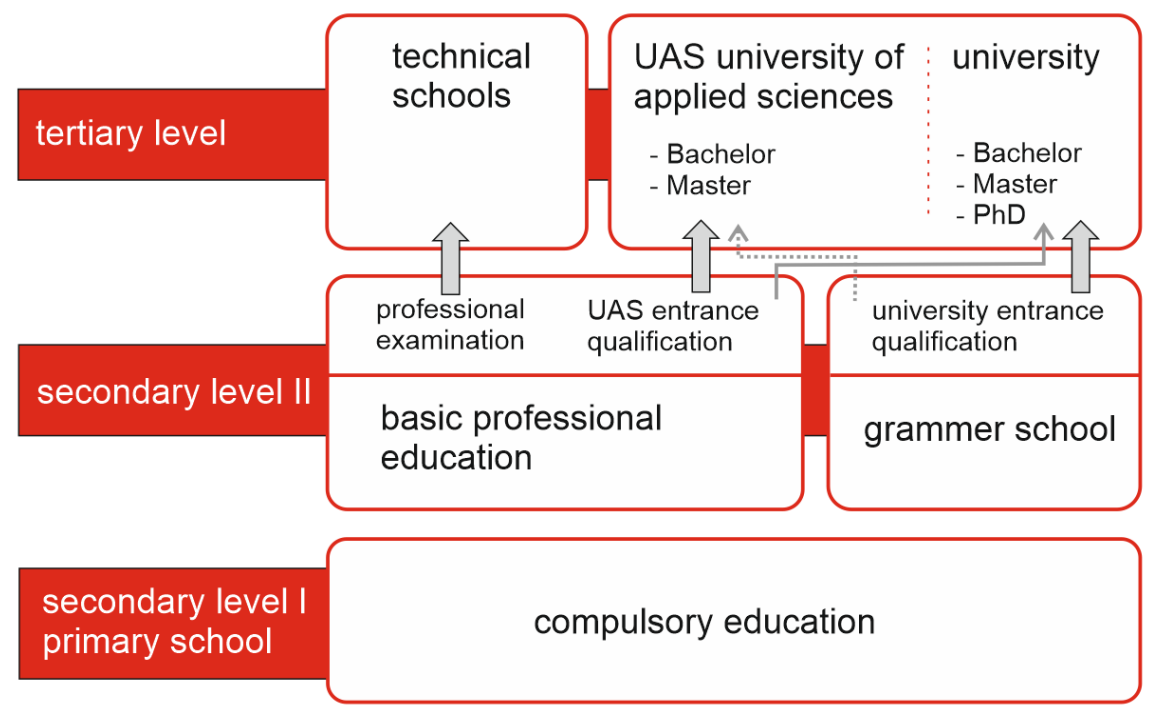

Figure 2. Three-level structure of the Swiss educational system. An apprenticeship and a vocational baccalaureate qualify students to enter the tertiary level and study at a university of applied sciences.

Photonics as a discipline was not represented in the Swiss educational landscape until 2015. Only few contents in the fields of optics and electronics can be found on different educational levels. In the field of apprenticeship in Switzerland there is the optician, the precision optician, the microtechnician, the physics laboratory technician, or the electronics technician who is educated in optics and/or electronics. At grammar school level, optics is taught as part of the physics lesson. At the level of technical colleges and universities, there were only engineering courses with special subjects in laser technology, optoelectronics, optical communication technology, image processing, etc.

Does Switzerland need further education and training in photonics? Is it necessary to offer photonics education at bachelor's and/or master's degree up to $\mathrm{PhD}$, or should photonic topics show up as a specialization in various technical university courses? There are various pros and cons for further training programs in photonics: 
- The cross-sectional thematic breadth of photonics makes it difficult to find a common denominator for a photonics bachelor or master program that is attractive for students.

- An important field of application of photonics - the laser - is already represented as a dominant element in many technical studies. Photonics brings together many different disciplines, some of which are only of marginal interest to a technician. Offers and contents in photonics should be designed in such a way that students can find and select suitable focal topics.

- Switzerland already offers many bachelor programs, some of which disappear from the market after only a few years. The question therefore arises whether it makes sense to offer a separate bachelor program for everything.

On the other hand, there are good arguments for a broad photonics education. Photonics is recognized worldwide as the key technology of the 21 st century. It enables numerous applications and is thus an "enabler" of important crosssectional technologies. Major initiatives such as "Industry 4.0 and IoT" and "Data Science" are based on photonics and open up new fields of application.

The photonics industry has enormous problems with junior employees. In the field of laser development, for example, it is very difficult to recruit suitable junior staff. In addition, it can be observed that around 80 percent of the laser specialists are "imported" from Germany. Switzerland has excellent technical colleges and universities, but there is no bachelor's or master's degree in photonics. Foreign countries show that trained photonics engineers "sell like hot cakes."

As an example, let's take a brief look at photonics education in Germany. The typical career of a photonics engineer in Germany often begins with a degree in physics or engineering. In the bachelor thesis or in the master courses students specialize in photonics. However, some universities have been offering courses in photonics for some years now. In 2015, there were 16 bachelor courses in photonics in Germany, for example in optical technologies, optometry, optoelectronics or laser technology. At master level, 22 programs were offered under titles like: Photonics, Laser Technology, Optical Technologies, Vision Science, Opto-technology and Image Processing or Ophthalmic Optics/Optometry.

\section{SWISSMEM CONCEPT: BACHELOR IN PHOTONICS}

The profile of a photonics engineer resembles an intersection of an engineer and a physicist. The contents must go so far into physics that it remains understandable for the engineer and interesting for the physicist. Despite many open questions, the Swissmem Photonics Division with its approximately 30 members has worked intensively on the "profile" of a photonics engineer. They focused on bachelor students of UAS because they identified the greatest need there. The goal was to provide engineers at bachelor level with a solid expertise in optics and photonics. In mid-2015, a position paper entitled "Bachelor in Photonics" was presented that defined a requirement profile and recommended topics and priorities for a photonics curriculum [2]. Most important key messages of the position paper are summarized below:

Motivation for a "Bachelor in Photonics":

- the shortage of skilled workers in industry (in various areas of photonics and optics)

- the recruiting of skilled personnel from abroad is not sufficient and cannot be the only way out

- the lack of basic knowledge in photonics among the graduates of the bachelor courses available today

- the missing clientele for master courses (to be developed at a later date)

Increasing demand for young photonics engineers:

The future demand of photonic companies and system providers ("customers" of the former) for young engineers is about the same, i.e. 12 - 24 graduates each, or a total of 25 - 50 graduates per year. This indicates that two different programs (local and/or thematic) should be possible.

Requirement profile for a photonics bachelor graduate:

A solid basic education is crucial. This means the following: mathematical and physical basics of optics; technical as well as methodological competences for working in industry such as project work and industrial processes - in short: the graduates must master the basics in photonics.

Specializations in the field of specific applications or technologies should not be considered in bachelor programs. Specialized skills have to be acquired either in the companies "on the job", in CAS courses or in master programs. 
Training focus for a "Bachelor in Photonics" (recommendation):

- Physics: specialization in optics and semiconductor physics

- Computer Science: programming and application; image processing

- Electrical Engineering: focus on analog electronics

- Optoelectronics: design of simple optical systems

- Photonic applications: Get to know applications and work with them, but no application-specific in-depth knowledge.

- Additional, important topics: mechanical design, handling of optics, standards, manufacturing processes, optical specifications, measurement and production metrology, materials engineering

$\underline{\text { Role of the Swissmem Photonics Section: }}$

Active role of Swissmem in the bachelor program:

- to provide experts (from industry) for specialist lectures

- to open companies for students: insight into the photonics business; project, semester and diploma thesis

- to provide hardware, selected equipment, specific knowledge and expertise

Active role of Swissmem in student acquisition:

- Advertising for jobs in the photonics / optics industry

- Training of apprentices, with potential for further photonics education

- Lectures for potential students by "alumni" from industry, who explain their "successful" careers and those of their colleagues

- Presentation of the attractiveness and sustainability of the photonics industry

This view on photonics through the eye of industry and the approach derived from it were convincing. Two universities of applied sciences in Switzerland adopted the Swissmem concept and established a bachelor's degree in photonics. While the HTW in Chur decided to establish a complete photonics bachelor program, the NTB in Buchs developed a photonics profile according to the Swissmem proposal and included photonics into the existing Bachelor in Systems Engineering. Figure 3 shows schematically the structure of the Bachelor program in System Engineering.

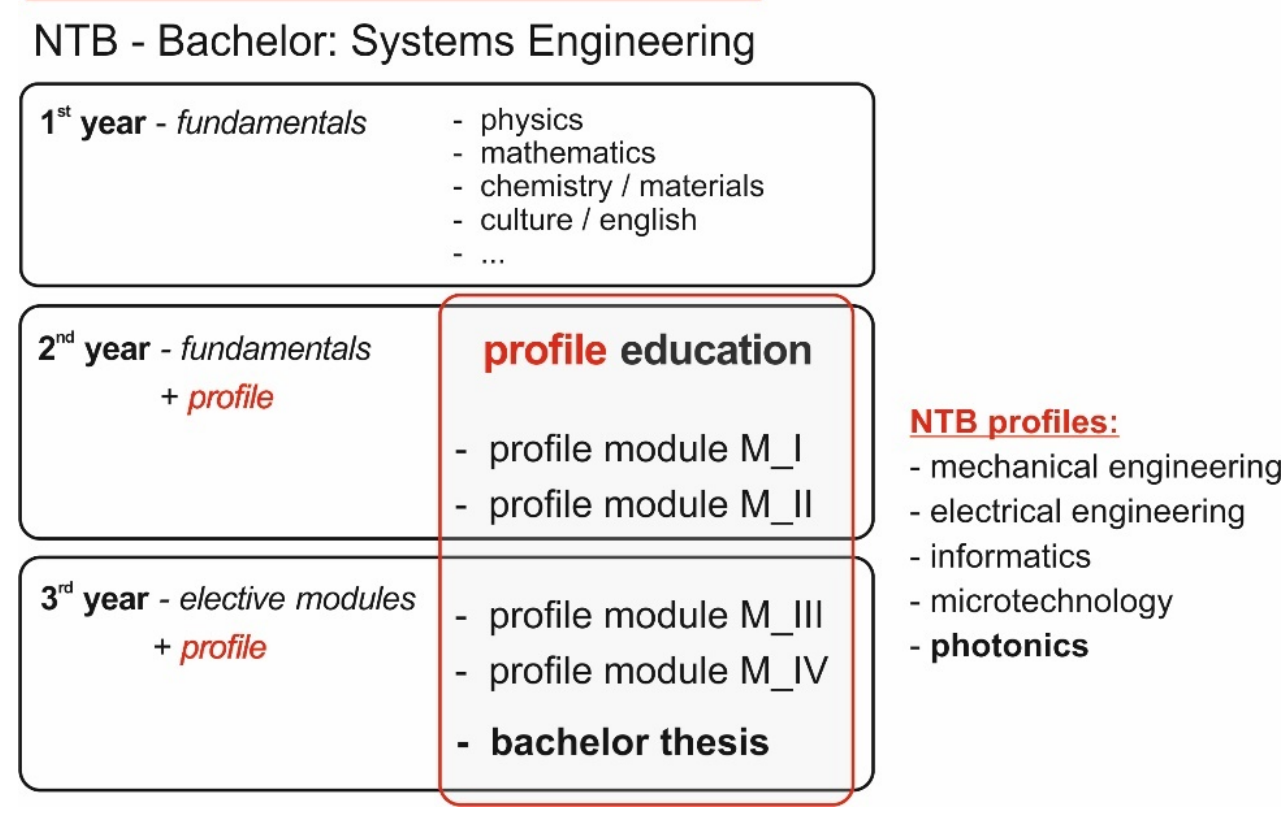

Figure 3. Structure of the Bachelor in Systems Engineering at NTB. The first year covers the fundamentals and is the same for all students. From the third semester onwards, each student can choose from one of the five profiles offered. 
The Bachelor in Systems Engineering is a study program with 180 ECTS that runs for six semesters. The first year of study is the same for all students and covers the basics of engineering in physics, chemistry, material science, mechanical design, electrical engineering and computer science. From the third semester onwards, each student can choose from one of the five profiles offered. The profile modules run for four semesters and are rounded off by further engineering basics as well as elective modules. The profile also includes the bachelor thesis and accounts for about $40 \%$ of the total study program.

\section{DEVELOPMENT OF A PHOTONICS CURRICULUM}

In autumn 2015, a working group was set up to develop the curriculum for a photonics profile in accordance with the Swissmem proposal. A group of five lecturers and ten scientific assistants from the fields of microtechnology, optics and electronics worked out learning objectives, competences and the contents of the individual modules over a period of five months. On the one hand, the key messages of the position paper "Bachelor in Photonics" were considered and on the other hand, the strengths in R\&D of the participating institutes were taken into account.

Figure 4 shows an intermediate step in the development of the curriculum, where the defined learning objectives were synchronized with the planned module topics. The conformity of competences and contents with Swissmem's recommendations is shown in red.

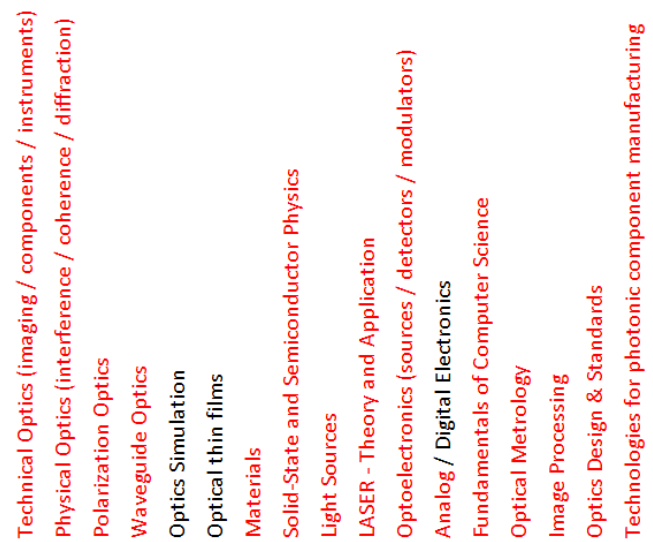

\begin{tabular}{|c|c|c|c|c|c|c|c|c|c|c|c|c|c|c|c|c|c|c|c|}
\hline SWISSMEM concept & & Competences of a photonics bachelor & & & & & & & & & & & & & & & & & \\
\hline \multirow{2}{*}{$\begin{array}{l}\text { Physics: specialization in optics and } \\
\text { semiconductors }\end{array}$} & 1 & $\begin{array}{l}\text { The graduate understands the basics of ray and wave } \\
\text { optics. }\end{array}$ & $x$ & $x$ & $x$ & $\mathrm{x}$ & $\mathrm{x}$ & $\mathrm{x}$ & & & $\mathrm{x}$ & $\mathrm{x}$ & $\mathrm{x}$ & & & $\mathrm{x}$ & $\mathrm{x}$ & & \\
\hline & 2 & $\begin{array}{l}\text { The graduate understands the interaction of light } \\
\text { with matter. }\end{array}$ & & & & $\mathrm{x}$ & & & $x$ & $x$ & $\mathrm{x}$ & $\mathrm{x}$ & $\mathrm{x}$ & & & & & & \\
\hline $\begin{array}{l}\text { Electrical Engineering: } \\
\text { Focus on analog technology }\end{array}$ & 3 & $\begin{array}{l}\text { The graduate understands the signal chain from the } \\
\text { analog signal to digital processing. }\end{array}$ & & & & & & & & & & & $\mathrm{x}$ & $x$ & $x$ & & $\mathrm{x}$ & & \\
\hline $\begin{array}{l}\text { Computer Science: Programming and } \\
\text { Application, Image Processing }\end{array}$ & 4 & $\begin{array}{l}\text { The graduate knows how to use software systems for } \\
\text { photonics }\end{array}$ & & & & & $\mathrm{x}$ & & & & & & & & $\mathrm{x}$ & & $\mathrm{x}$ & & \\
\hline \multirow{6}{*}{$\begin{array}{l}\text { Optoelectronics: } \\
\text { designing simple optical systems } \\
\text { (classic and gauss/wave optics), } \\
\text { optical applications }\end{array}$} & 5 & $\begin{array}{l}\text { The graduate understands the structure of photonic } \\
\text { systems and is able to describe it }\end{array}$ & $x$ & $x$ & $x$ & $\mathrm{x}$ & & $\mathrm{x}$ & & & $x$ & $\mathrm{x}$ & $\mathrm{x}$ & & & & $\mathrm{x}$ & $\mathrm{x}$ & \\
\hline & 6 & $\begin{array}{l}\text { The graduate understands the function of photonic } \\
\text { systems and can design and construct them. }\end{array}$ & $x$ & $x$ & $x$ & $x$ & $\mathrm{x}$ & $\mathrm{x}$ & $x$ & & $x$ & $x$ & $x$ & $x$ & & & $x$ & $x$ & \\
\hline & 7 & $\begin{array}{l}\text { The graduate understands the function of photonic } \\
\text { systems and can realize them. }\end{array}$ & $x$ & $x$ & $x$ & $x$ & & $x$ & $x$ & & $x$ & & $x$ & $x$ & $x$ & & $x$ & $x$ & \\
\hline & 8 & $\begin{array}{l}\text { The graduate can select and evaluate photonic } \\
\text { components }\end{array}$ & $x$ & $x$ & $x$ & $x$ & $x$ & $x$ & $x$ & & $x$ & & $x$ & & & & $x$ & $x$ & \\
\hline & 9 & $\begin{array}{l}\text { The graduate knows the manufacturing processes of } \\
\text { optical components }\end{array}$ & & & & & & & $x$ & & & $x$ & & & & & & $x$ & $x$ \\
\hline & 10 & $\begin{array}{l}\text { The graduate knows optical measuring methods and } \\
\text { is able to use them }\end{array}$ & $x$ & $x$ & $x$ & $x$ & $x$ & & & & $x$ & & $x$ & & $x$ & $x$ & $x$ & & \\
\hline
\end{tabular}

Figure 4. The photonics curriculum was elaborated using quality function deployment methods. The present QFD matrix shows, how well the planned photonic topics meet the defined competences of a photonics bachelor. 
In a next consolidation step, the different topics were combined into modules and arranged according to the required prior knowledge of the students. In addition, boundary conditions resulting from the parallelization in the timetables of all five profiles had to be taken into account. As a result, a very demanding curriculum was defined, which started in September 2016 for the first time with 10 students.

Figure 5 summarizes the contents of the photonics profile at NTB. The contents are sorted thematically. In brackets, the module abbreviation gives information on the module in which the courses take place. In addition to the fundamentals in optics and electronics, various specialization topics in photonics are offered. The photonics profile has a considerable amount of practical work in the form of practical training, laboratory exercises and project work. In addition, excursions to partner companies are carried out during the four profile semesters and the lessons are supplemented by expert talks from industry.

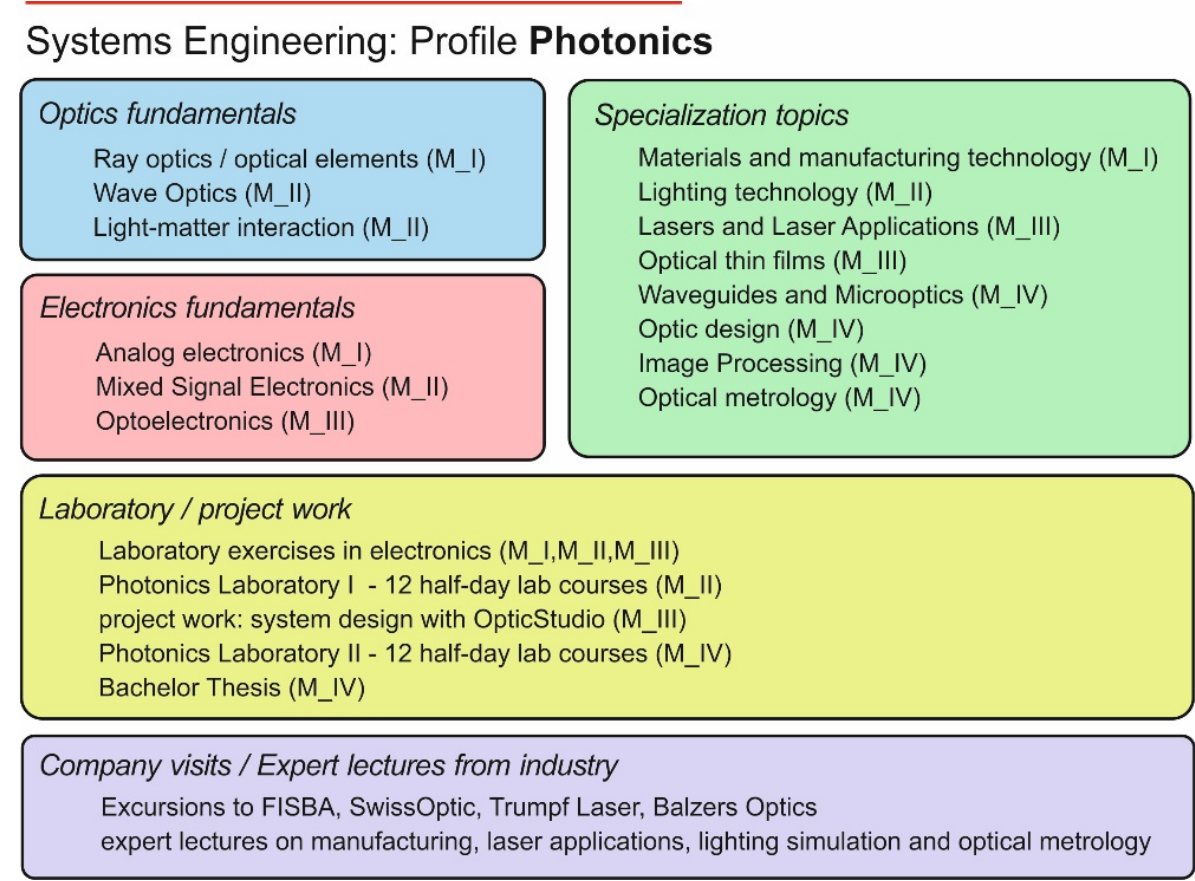

Figure 5. Thematically arranged overview of the photonics courses offered within the four profile modules in the second and third year of the Bachelor in System Engineering at NTB.

After a long period of hard work, preparation and planning, the success of all efforts was celebrated for the first time in 2018. On September 21, 2018, the first 10 bachelor graduates in photonics in Switzerland received their diploma at the NTB Interstate University of Applied Sciences in Buchs. Seven of the ten photonics students started their careers directly in the photonics industry while the others decided to continue with their master studies in Switzerland.

\section{MASTER IN PHOTONICS - THE NEXT STEP}

Shortly after the bachelor programs had started, the first voices were raised calling for master courses in photonics: "Concentrating on the bachelor's degree could entail the risk that the photonics training only reflects the status quo". "Only on master and $\mathrm{PhD}$ level it is possible to train people who are able to develop and implement new applications". This opinion was also expressed by the industry: "Offers such as Master and $\mathrm{PhD}$ degrees are complementary and important for Switzerland". Nevertheless, the question arose whether Switzerland needed its own master program in photonics. An important argument against this is the "critical mass". A rule of thumb says that for every five bachelor graduates there is one master student. Projected onto Swissmem's bachelor forecast, this would result in a maximum of ten master students per year. 


\subsection{The MSE concept in Switzerland}

Switzerland as a base for tertiary education is too small to offer everything everywhere. It was therefore a must that all seven Swiss universities of applied sciences work together and cooperate at master level. In 2008, this cooperation resulted in the MSE master concept. The Master of Science in Engineering (MSE) was designed as a Swiss UAS master course with a duration of three semesters and 90 ECTS. The basic modules are exclusively taught at certain central locations. All students must take modules at Zurich, Bern or Lausanne. These centralized modules are divided into three categories. The TSM modules impart technical scientific specializations. The FTP modules cover the fundamental theoretical basics and the CM modules complete the offer with economic, methodical and cultural contents. These centralized modules comprise 30 ECTS, or one third of the credits required. The other two thirds of the training take place decentral at the respective universities of applied sciences. The students work on advanced projects in their chosen subject area and attend supplementary courses. This part of the training also accounts for 30 ECTS. The master thesis with 30 ECTS, which is also written locally at the respective university, rounds off the master program. The Swiss MSE concept is visualized in Figure 6.

\section{MSE: Master of Science in Engineering}

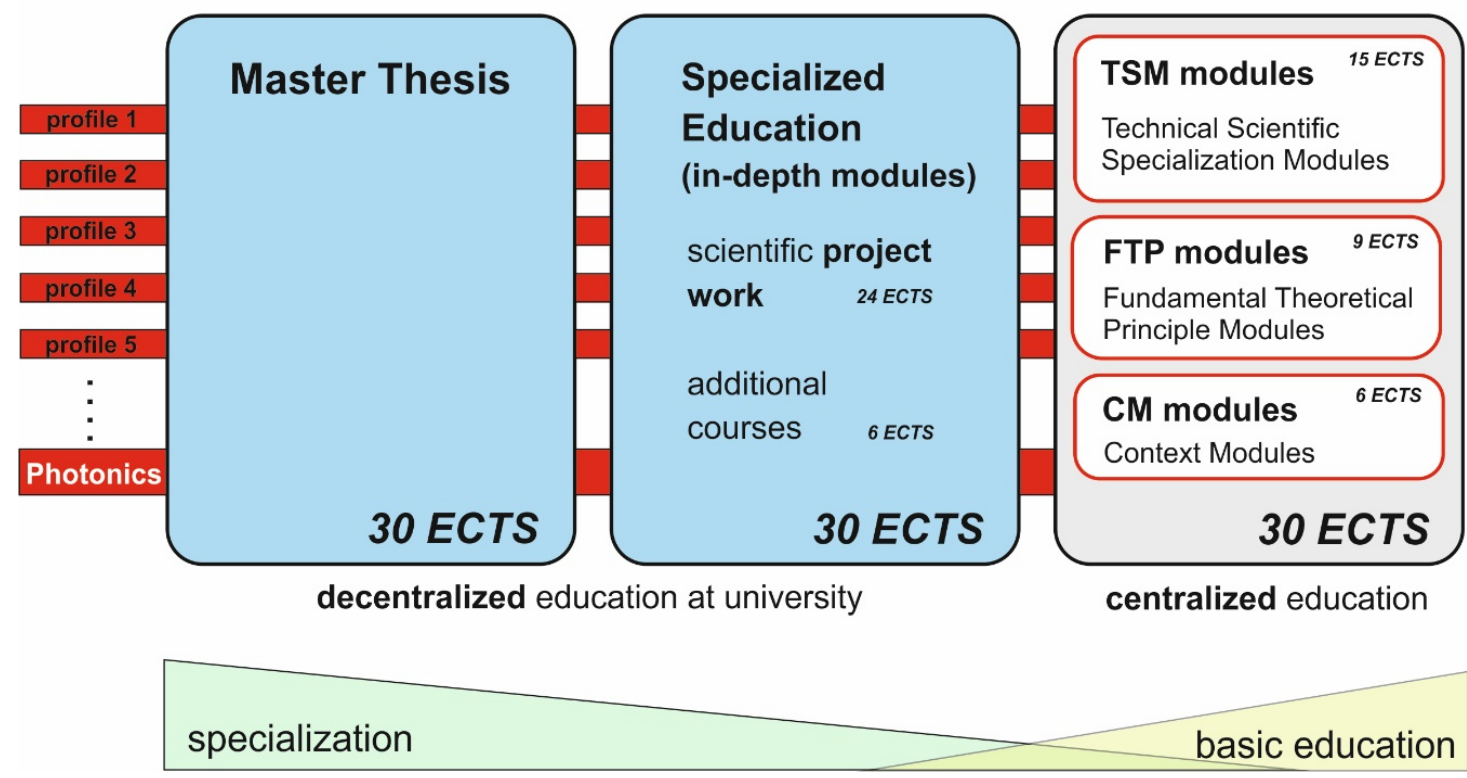

Figure 6. Swiss MSE master concept: 30 ECTS are acquired centralized in the form of central modules. 60 ECTS are acquired at the local UAS in the form of project work, supplementary modules and the master thesis.

The MSE master training is organized in thematic profiles. A profile corresponds to the subject area in which the master student wants to specialize. In the actual MSE curriculum, photonics is not present as a profile.

\subsection{Swissmem application for an MSE profile "Photonics"}

Once again, triggered by the Swissmem Photonics Section, a working group consisting of representatives of industry and universities started to work on a "MSE Photonics Profile" in January 2017. Swissmem assured its support in the development and operation of the profile.

Industry members offered concrete collaboration in the design of the MSE profile as well as in the acquisition of master students. They also confirmed further support for lobbying of key decision- and policy-makers, for thinking outside the box to find the optimum solution for educational requirements and for networking with foreign universities and photonics institutions. Concerning the operation of the photonics profile, it is planned to provide topics for semester projects and to offer industrial partnerships for the execution of the master thesis. In addition, the universities of applied sciences are provided with missing hardware and selected equipment. 
Furthermore, there is a strong commitment of the photonics industry concerning marketing activities. In addition to student acquisition, advertising for jobs in the photonics/optics sector should be strengthened. One central idea is the promotion of photonics by "alumni" from industry that give lectures on photonics perspectives for potential students, explaining their "successful" careers in exemplary fashion. Overall, the attractiveness and sustainability of the photonics industry should be highlighted.

In several working sessions, the planned thematic topics as well as proposals for new TSM and FTP modules were developed. Foreign master programs were analyzed and the need for graduates for industry was compared with forecasts from the participating universities of applied sciences. Finally, in June 2018, a joint application was submitted to the MSE Steering Committee, in which the project team applied for a separate photonics profile within the MSE.

In autumn 2018, a "small profile" Photonics was finally approved. In Nov. 2018, a profile commission consisting of representatives from all seven Swiss universities of applied sciences was appointed for the task of specifying learning objectives and module content and for preparing all the necessary formal prerequisites by autumn 2019 . The start of the new profile within the MSE is planned for the autumn semester 2020.

\section{STRENGTHENING PHOTONICS IN SWITZERLAND FOR THE FUTURE}

Also in 2019, Switzerland will have to make an effort to maintain its leading position in the field of photonics. In addition to new photonics trainings programs, this also requires structured research funding, which will give Swiss industry the same opportunities as its international competitors.

Many countries in the world have recognized the significance of photonics and are investing massively in the development of photonic technologies. In Germany, for example, 100 million euros are invested annually in photonics projects and infrastructure, in France and England even 150 million euros. In the USA, the government is providing over 1 billion US dollars for photonic developments and in Korea the almost unimaginable sum of 4.5 billion euros is available for photonic developments in 2014 - 2020.

In this environment, the Swiss photonics industry, which is still very efficient today, but mainly small and medium-sized, has a massive competitive disadvantage. For Switzerland it is indispensable to continuously convert the latest findings into marketable and forward-looking products.

Considering that photonics is an enabler for many important industrial sectors in Switzerland, the Swissmem Photonics Section asks the Swiss federal government to pursue an adequate research policy in the field of photonics. For this purpose, a "White Paper Photonics Switzerland" [3] was jointly elaborated by a group of experts from industry, associations, research and universities. As an important Swiss university of applied sciences and research center in the heart of the Swiss photonics cluster Eastern Switzerland, the NTB was actively involved in the development of this white paper. The focus is on the demand for government funding for projects in favor of the following forward-looking focuses for Swiss industry:

- Advanced Manufacturing

- Industry 4.0

- Smart Sensing, Digitization and Measurement Technology

- Data and Image Processing, Augmented and Virtual Reality

- Medical Technology

- Communication Systems

The funded projects are intended to incubate and promote important skill functions such as:

- Development of photonic system competencies

- Provision of photonic process chains

- Access of markets with rapid growth potential

- Expansion of photonics technologies in Switzerland 


\section{CONCLUSION}

Over the past five years, Switzerland has undergone major changes in the field of photonics. Thanks to a well-positioned photonics industry and dedicated professional associations such as Swissmem and Swissphotonics, new milestones were set in the area of training and further education, but also in research and development. For example, two bachelor's degree programs with a focus on photonics were launched on the initiative of industry in 2016. A new photonics profile has also been established at master level, which will guarantee a consistent bachelor and master education in photonics in the future. Politicians have also recognized that targeted research funding in the photonics sector is a basic prerequisite for innovation and growth in the sector, so that photonics will become a "key enabling technology" in Switzerland as well.

\section{ACKNOWLEDGEMENT}

First, I would like to thank the management of NTB. They listened to the demands of the photonics industry and initiated a photonics profile within the NTB Bachelor program Systems Engineering. I would also like to thank the Swissmem Photonics Division, and in particular Werner Krüsi and Brigitte Waernier-Gut, for their commitment to photonics education in Switzerland. Last but not least I would like to thank the NTN Swissphotonics, in particular Christoph Harder, who is actively involved in all political and economic committees every day, to fight for the interests of photonics in Switzerland.

\section{REFERENCES}

1. Optech Consulting, "Photonics in Switzerland - Economic Importance", 2016 (in German), https://www.swissphotonics.net/libraries.files/swiss_photonics_market_report_20161.pdf (25.04.2019)

2. Swissmem Photonics Division, "Position Paper: Bachelor in Photonics", 2015 (in German), http://www.swissphotonics.net/libraries.files/Positionspapier_Bachelor_Photonics_finall.pdf (25.04.2019)

3. Swissmem Photonics Division, "White Paper Photonics Switzerland", 2018 (in German), https://www.swissmem.ch/fileadmin/user upload/Swissmem/Documents/Documents/Other/bb2018/18 White Pape r Photonics Switzerland.pdf (25.04.2019) 